\title{
Correction to: First reported case of penile prosthesis infection from brucellosis: case report
}

Nabil N. Moohialdin ${ }^{1 *} \mathbb{0}$, Ahmad Shamsodini ${ }^{1}$, Steven K. Wilson ${ }^{2}$, Osama Abdeljaleel ${ }^{1}$, Ibrahim Alnadhari ${ }^{1}$ and Ausama Saadi Abdulmuhsin ${ }^{1}$

\section{Correction to: Afr J Urol (2020) 26:82} https://doi.org/10.1186/s12301-02000090-1

Following publication of the original article [1], the authors identified an error in an author's name.

The incorrect name was: Nabil Nabil Moohialdin

The correct author name is: Nabil N. Moohialdin

The author group has been updated above and the original article [1] has been corrected.

\section{Author details}

${ }^{1}$ Urology Department, Al-Wakra Hospital, Hamad Medical Corporation, Al

Wakrah, Qatar. ${ }^{2}$ Institute of Urological Excellence, Indio, CA, USA.

\section{Reference}

1. Moohialdin NN, Shamsodini A, Wilson SK et al (2020) First reported case of penile prosthesis infection from brucellosis: case report. Afr J Urol 26:82. https://doi.org/10.1186/s12301-020-00090-1

\section{Publisher's Note}

Springer Nature remains neutral with regard to jurisdictional claims in published maps and institutional affiliations.

Published online: 08 February 2021

The original article can be found online at https://doi.org/10.1186/s1230 1-020-00090-1.

*Correspondence: dr.nabilalhajj@gmail.com

${ }^{1}$ Urology Department, Al-Wakra Hospital, Hamad Medical Corporation,

Al Wakrah, Qatar

Full list of author information is available at the end of the article 